\title{
Coulisses
}

Revue de théâtre

8 | Eté 1993

Varia

\section{Théâtre Universitaire de Besançon}

\section{(2) OpenEdition}

1 Journals

Édition électronique

URL : http://journals.openedition.org/coulisses/2537

DOI : $10.4000 /$ coulisses. 2537

ISSN : 2546-9460

Éditeur

Presses universitaires de Franche-Comté

\section{Édition imprimée}

Date de publication : 1 juillet 1993

Pagination : 16-17

ISSN : 1150-594X

\section{Référence électronique}

«Théâtre Universitaire de Besançon », Coulisses [En ligne], 8 | Eté 1993, mis en ligne le 15 mars 2019, consulté le 30 octobre 2019. URL : http://journals.openedition.org/coulisses/2537 ; DOI : 10.4000/ coulisses. 2537

Ce document a été généré automatiquement le 30 octobre 2019.

Coulisses 


\section{Théâtre Universitaire de Besançon}

\section{Le metteur en scène}

\section{Joseph Melcore}

18-09-58

1 Joseph Melcore est diplômé de l'Université d'Aix en Provence en Recherche et animation théâtrales, formation en trois ans dirigée par Pierre Voltz. Il a participé à plusieurs stages, en particulier avec le Roy Hait Théâtre de Lyon (travail sur la voix), avec JeanLouis Hourdin et Ariane Mnouchkine (direction d'acteur). Depuis sa création en 1986, Joseph est animateur-metteur en scène du T.U.F.C. Il est en outre responsable des stages pratiques de théâtre à la Faculté des Lettres. Simultanément, il exerce la profession de documentaliste dans un collège bisontin.

Joseph Melcore et Irina Popescu (lasi)

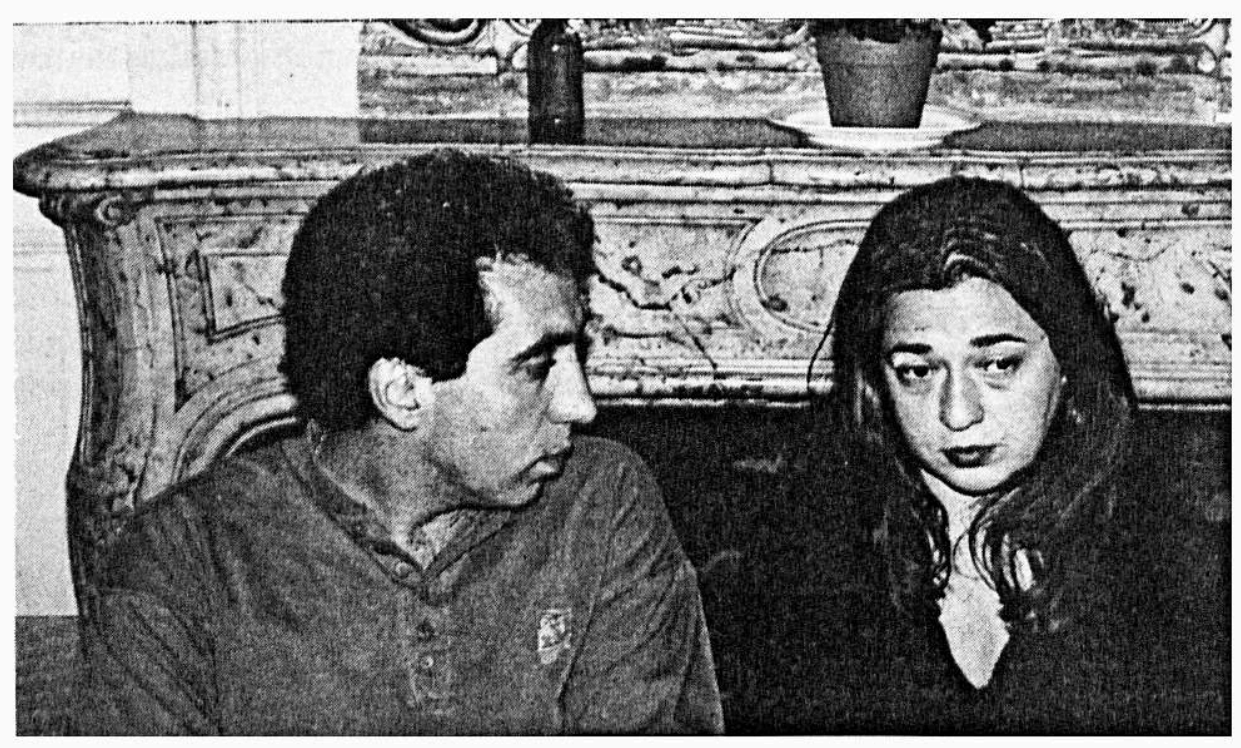




\section{Son point de vue}

2 Il nous a semblé important de travailler sur la résonance que peut avoir un texte appartenant au passé, en quoi il nous concerne ici et maintenant, comprendre pourquoi Shakespeare peut être «notre contemporain» et comment la fable, les personnages, leurs actions peuvent éclairer notre condition d'homme du XXème siècle. Toucher par là l'universalité du texte. Dans Cymbeline les personnages sont en permanence tiraillés entre des forces de vie, d'amour et des forces de mort, de mal qui se combattent; le problème est de rendre visible cette lutte. Par ailleurs, la pièce n'a rien de réaliste, et il nous a paru nécessaire de rendre compte d'un certain merveilleux chrétien où s'opposent anges et démons.

3 Nous travaillons plus particulièrement sur les forces du mal, représentées par des personnages diaboliques omniprésents et capables de toutes les métamorphoses. Ils rôdent et hantent les lieux prêts à revêtir toutes les apparences, à utiliser tous les expédients. La Reine, Cloten, Iachimo, en sont les personnages emblématiques. Posthumus est celui qui, plus que tout autre doit au cours d'épreuves choisir entre l'ambition, l'argent, le sexe... et l'amour.

\section{Les étudiants sur scène}

Laure BACCHETTA

Florence CABOT

Cedric CHARLIER

Philippe couLON

Philippe GUERREIRO

Cathy HALLE

Hélène MERCIER

Frédérique MIGNOT

Patricia ZOUGGAR 


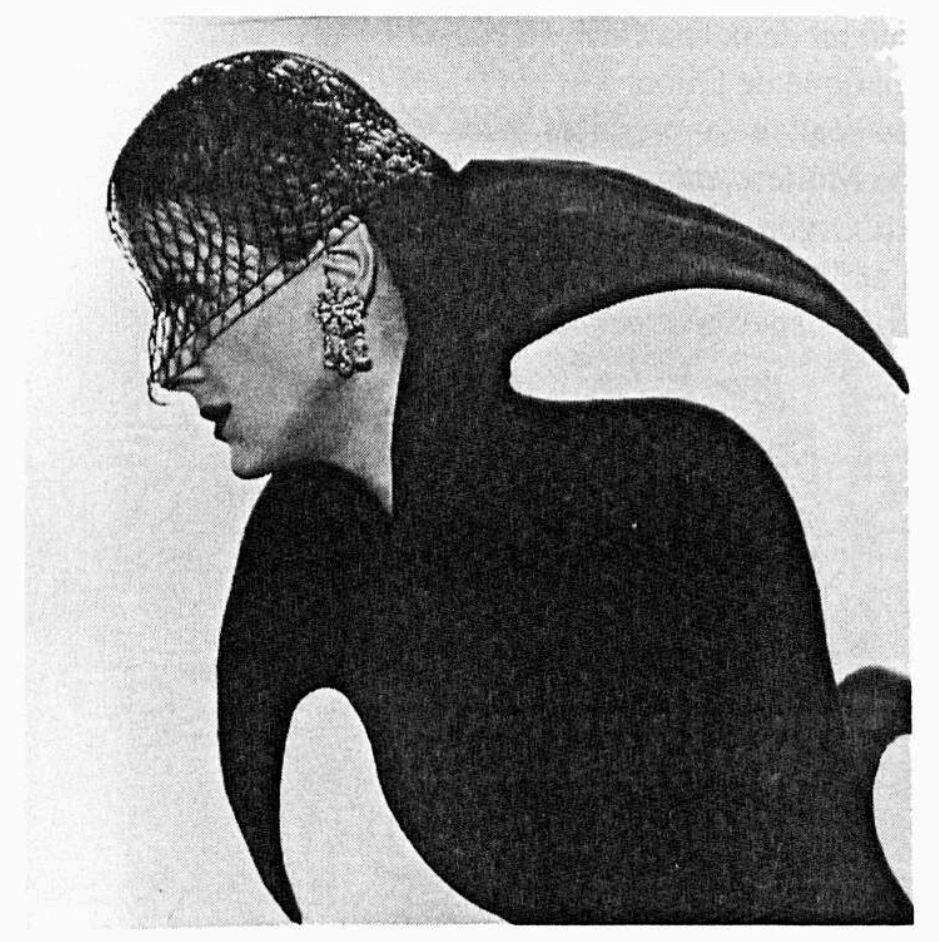

\section{Le T.U.}

4 Fondé en 1986, le Théâtre Universitaire de Franche-Comté (T.U.F.C.) est une association loi 1901 présidée par une enseignante - Lucile Garbagnati - et dont la création artistique est assurée par un professionnel - Joseph Melcore. Chaque année, le T.U.F.C. crée un spectacle et le reprend l'année suivante pour le diffuser en France et à l'étranger (Belfort, Dijon, Bordeaux, Liège, Cologne, Ottawa, Vilnius, Edinburgh, ...). Le T.U.F.C. organise tous les deux ans à Besançon des Rencontres Internationales Théâtre et Université, qui accueillent des théâtres universitaires venus du monde entier (Mexique, Lituanie, Italie, Ouzbékistan, Allemagne, ...) ainsi que des professionnels. Le T.U.F.C., c 'est aussi la responsabilité de la pratique des enseignements théâtre de la Faculté des Lettres, l'organisation de colloques sur le théâtre, d'un cycle de conférences sur le théâtre dans le cadre de l'Université Ouverte et une revue théâtrale biannuelle Coulisses. 